\title{
Design Fires for Deliberately Lit Fire Scenarios in which Bottled Petrol is used as the Accelerant
}

\author{
PAUL L. E. RICHARDS ${ }^{1},{ }^{*}$ CHARLES M. FLEISCHMANN ${ }^{2}$, and MICHAEL J. SPEARPOINT ${ }^{2}$ \\ ${ }^{1}$ Beca Fire International \\ Christchurch, New Zealand \\ paul.richards@beca.com \\ ${ }^{2}$ Department of Civil and Natural Resources Engineering, \\ University of Canterbury \\ Private Bag 4800 \\ Christchurch, New Zealand \\ *Corresponding author: charles.fleischmann@canterbury.ac.nz
}

\begin{abstract}
Deliberately lit fires can be viewed as a wide range of possible scenarios. How and when deliberately lit fires are included within a Fire Engineering Brief is primarily a political decision for the regulator. In New Zealand the proliferation of single means of escape high-rise residential buildings has prompted concern over a deliberately lit fire within the stairwell that can compromise the safety of all of the building occupants. This paper presents a brief look at the fire statistics for deliberately lit fires to determine if the single means of escape buildings exhibit a greater propensity to deliberately fires.

Although the statistics do not show a significant increase in deliberately lit fires in attached accommodation buildings, the perception that a deliberately fire in the stairwells should be considered in the Fire Engineering Brief, has motivated this study. A series of experiments were carried out to simulate a glass bottle filled with petrol being thrown into a stairwell. Experiments were conducted using both timber and metal stairs with both plasterboard and concrete block walls. The size of the petrol bottle and location of the ignition were also investigated. The results of this work can be used to develop the design fire for a single petrol bottle thrown into a stairwell or other noncombustible enclosure.
\end{abstract}

KEYWORDS: fire scenarios, design fire, arson, accelerant

\section{INTRODUCTION}

Deliberately lit fires may be viewed as a spectrum ranging from the ignition of materials located within the compartment through large amounts of flammable liquids poured throughout the space. In the case of using a match to ignite materials present in the compartment, the fact that the fire has been deliberately lit has virtually no impact on the development of the resulting fire and standard design fire curves will remain adequate to test the resulting fire. At the other end of the spectrum the use of a large quantity of flammable liquids ( $>20$ litres) may be considered an introduced fuel load in some cases. The growth rate of the resulting fire from such an event will be largely determined by the introduced flammable liquid rather than the objects present in the building. To design for these types of incident, special design fire curves are required as the design fires currently used by fire engineers are not applicable.

Between these two extremes lie incidents where the method used to start the fires does impact on the resulting fire growth however fire development is still largely determined by the objects present in the compartment. As the severity of the fire increases the number of actual fire incidents drops off dramatically, this puts severely challenging deliberately lit fires involving large quantities of flammable liquids on a similar likelihood to bombing of the buildings, they are low-probability/high-consequence events [1]. Designing structures to survive the blast of a bomb or the burning of large quantities of flammable liquid represent significant challenges to the engineering community and impose significant costs onto the client. For most buildings it is not practical to design against such rigorous events so the use of bombs and explosive fires is not considered here.

This study was motivated by the recent proliferation of single means of escape residential buildings being built in New Zealand. According to the Compliance Documents [2], a sprinklered multistory residential building is allowed to have only a single means of escape as long as the highest occupied floor level is less 
than $25 \mathrm{~m}$ above the final exit. With floorspace at a premium, owners are looking to maximise the living space while minimising the common areas, including stairways. Thus more and more multistory apartment buildings are being designed with only a single means of escape (SME). Recently, a number of buildings have been built using the performance based requirements of the New Zealand Building Code which exceeds the $25 \mathrm{~m}$ threshold. These performance based design buildings have been justified using a comparative risk assessment methodology as discussed in Reference [3].

Clearly the single means of escape building is vulnerable to a deliberately lit fire occurring in the only stairwell in the building. This vulnerability was identified by the Department of Building and Housing (DBH) in their recent determinations on a single means of escape residential building [4-6]. According to the independent expert acting for the DBH [7]:

"Single means of escape buildings are more vulnerable than buildings with two stairways to an arson attack, or other fire, in the stairway... It is of particular concern that the sophisticated analysis carried out by the expert has shown that people are not safe from smoke logging if they try to escape though a stairway that has been the subject of an arson attack, even though the stairway is open to air on one side. This should be brought out very clearly in the determination as a warning against engineers making subjective judgments as to how smoke will behave without carrying out the analysis. The fire in the staircase scenario should have been integrated into the risk analysis, modifying the calculated 'margin'.”

Because the stairwells are constructed with noncombustible walls and stairs, the only fuel available would be introduced. Therefore, in their determination, the DBH used a $1 \mathrm{MW}$ fire for $60 \mathrm{~s}$ within the stairwell to simulate a deliberately fire from 1 litre of petrol. However, a review of the literature shows that design fire data for deliberately lit fires is limited especially for fires involving accelerants. Thus this research focused on quantifying deliberately fire within a stairwell. Previous work by Putorti et. al. [8] looked at flammable liquid spill fires on porous and nonporous floors with peak heat release rates of $770 \pm 120 \mathrm{~kW}$ from a 1 litre spill. For carpeted surfaces the peak heat release was less at $460 \pm 30 \mathrm{~kW}$. This work was limited to controlled spills rather than a spill resulting from a shattering glass bottle as reported here.

This paper starts by summarising a comprehensive review of the New Zealand Fire Incident Reporting System (FIRS) data over an 11 year period for deliberately lit fires to determine which occupancies are at risk and characteristics commonly observed in deliberately lit fire. We will then describe a series of experiments designed to quantify the heat release rate from a glass bottle filled with common petrol thrown into a noncombustible stairwell. The results in this paper are intended to give designers the information they require to determine the design fire from a deliberately fire in a noncombustible enclosure.

\section{REVIEW OF INTENTIONALLY LIT FIRE STATISTICS}

The New Zealand Fire Service maintains a database of national fire statistics compiled from their Fire Incident Reporting System (FIRS). A review of the database for the 11 year period from 1996 through 2006 gives a total dataset of 9606 deliberately lit fires. A comprehensive review of the deliberately lit fire statistics over this 11 year period can be found in Reference[9]. Only a summary of these statistics has been included in this paper.

Over this eleven year period there was an average of 873 deliberate lit fires per year. The annual deliberately lit fire rate peaked at 1003 incidents in 1997 and has since been trending downwards slightly. The average number of incidents in the five years between 2002 and 2006 was 847 per year compared with an average of 924 incidents per year between the years 1996 and 2000. This represents an 8.3\% reduction in the annual deliberately lit fire rate. The 9606 fires deliberately lit structure fires makes up $13.3 \%$ of the 72539 structure fires attended by the Fire Service between 1996 and 2006. These deliberately lit fires resulted in 28 fatalities and another 157 moderate or life threatening injuries. There was also another 127 slight injuries. The 28 fatalities represent $10.6 \%$ of the overall death toll from structure fires and the 157 injuries represent $9.8 \%$ of the total structure injury rate. On the basis of these results it appears that deliberately lit fires are under-represented in the overall fire casualty rate, reinforcing the belief that the crime of arson is a crime against property.

When assessing the potential risk posed by a deliberately fire it is useful to categorise the data by use or occupancy. Table 1 lists the occupancy classification in column 1 , column 2 gives the number of 
deliberately lit fires in the occupancy, column 3 gives the percentage of deliberately lit fires in the occupancy, and column 4 gives the percentage of all fires in the occupancy that are deliberately lit. From the results in Table 1, it can be seen that the majority of deliberately lit fires occurs in detached dwellings (38.9\%) yet this represents only $8.5 \%$ of the total fires that occurs in detached dwellings. The proportion of deliberately lit fires in detached dwellings (homes) is slightly higher in the US, where $51 \%$ of such fires occur in homes [3], [5], [10]. As the definition of 'home' has not been specifically defined, it has been taken to be the sum of attached and detached accommodation.

In contrast to homes, in detention accommodation only $1.9 \%$ of the deliberately lit fires occur here yet they represent $67.9 \%$ of the fires in this occupancy. It is readily apparent that a fire in a detention facility such as a prison is more likely to be deliberately lit than any other cause. It should also be mentioned that fires in care facilities are dominated by fires in psychiatric institutions, with $50.2 \%$ of all fires in such institutions being deliberately lit, a fire in a psychiatric institution is more likely to be deliberately lit than any other cause. Fires in education and crowd premises such as public houses are also highly likely to be deliberately lit. In both categories over $40 \%$ of all fires in these buildings are deliberately lit. Although the decision regarding the scenarios that should be included within a Fire Engineering Brief is a political decision, the results in Table 1 show that prisons, education, schools and crowd activities should be carefully considered.

Fires in the 'other' building category are dominated by fires in vacant structures. While fires in these buildings are also highly likely to be deliberately lit; the low occupancy of these structures means that they will not be considered further. The intended use of the building should to be taken into account, some buildings may experience an increased risk of attack for political, religious or ideological reasons and accurate statistics on these specific buildings may require further examination of the fire incident statistics. Such detailed review of the specific incidents was beyond the scope of this study.

Table 1. Likelihood that a fire will be deliberately lit by building occupancy.

\begin{tabular}{|l|c|c|c|}
\hline Building occupancy & $\begin{array}{c}\text { Total \# of } \\
\text { deliberately } \\
\text { lit fires }\end{array}$ & $\begin{array}{c}\text { \% of all } \\
\text { deliberately lit } \\
\text { fires }\end{array}$ & $\begin{array}{c}\text { \% of all fires } \\
\text { in occupancy }\end{array}$ \\
\hline Detention Accommodation & 181 & 1.9 & 67.9 \\
Education & 983 & 10.2 & 47.8 \\
Crowd & 947 & 9.9 & 42.6 \\
Open Grandstands & 123 & 1.3 & 32.2 \\
Care Accommodation & 287 & 3.0 & 16.6 \\
Working & 272 & 2.8 & 15.5 \\
Retail & 540 & 5.6 & 14.7 \\
Storage/Manufacturing & 723 & 7.5 & 11.0 \\
Attached Dwelling & 577 & 6.0 & 8.6 \\
Temporary Accommodation & 145 & 1.5 & 8.6 \\
Detached Dwelling & 3735 & 38.9 & 8.5 \\
Intermittent Use & 130 & 1.4 & - \\
Other & 963 & 10.0 & 42.6 \\
Overall & $\mathbf{9 6 0 6}$ & $\mathbf{1 0 0 . 0}$ & $\mathbf{1 3 . 3}$ \\
\hline
\end{tabular}

The results of the statistical analysis shown in Table 1 indicate that the proportion of deliberately lit fires in attached dwellings is $6.0 \%$. Therefore, the single means of escape building does not show a high susceptibility to deliberately lit fires. However, with only a single means of escape these buildings are vulnerable to a fire within the stairwell which has the potential of compromising the safety of all of the building occupants. Although the possible fire sources in a stairway under normal circumstances should be minimal anecdotal evidence indicates that the possibilities are endless. However it is considered by some that a 'Molotov cocktail' is the most common remote ignition device [11]. It was simply a judgment decision of experts working on behalf of the DBH that a 1 litre bottle of petrol posed a reasonable worst case deliberately lit fire. 


\section{EXPERIMENTAL SETUP \& PROCEDURES}

The experiments were designed to investigate the potential fire threat from a bottle of flammable liquid (petrol) thrown into a noncombustible stairwell with no resident combustible materials apart from possibly the stairs. The experiments were conducted in the University of Canterbury fire research laboratory under a $3 \mathrm{~m}$ by $3 \mathrm{~m}$ exhaust hood with a $4 \mathrm{~m}^{3} / \mathrm{s}$ exhaust rate [12]. The exhaust duct included standard oxygen depletion calorimetry with species measurements for $\mathrm{O}_{2}, \mathrm{CO}_{2}$, and $\mathrm{CO}$. For each experiment a video record was also obtained. There were no other experimental measurements included in this experimental programme.

A sacrificial concrete floor was poured over the permanent laboratory floor in case of spalling and to insure that the flammable liquid did not enter the floor drain. The two concrete block walls were used to contain the fire and simulate a stairwell corner. The walls also supported the flight of stairs that were included in some of the experiments. The stairs were positioned flush with one wall. The top end of the flight of stairs was positioned against the other wall. For the tests with a plasterboard wall, timber framing was placed against the block wall and sheets of standard plasterboard were screwed to the timber frame with screws located at $400 \mathrm{~mm}$ centres. The joins between the sheets of plasterboard were left unfinished. The flight of stairs was then positioned against the surface of the plasterboard. Fig. 1 is a schematic drawing of the laboratory floor plan showing the position of the exhaust hood, location of the walls and stairs, and point of ignition for the flammable liquid bottle.

The stairs themselves were constructed to meet the requirements of D1/AS1 [13]. The wooden stairs consisted of ten medium density fibreboard steps with a $180 \mathrm{~mm}$ riser and a $285 \mathrm{~mm}$ tread. The width of each step was $1000 \mathrm{~mm}$ and each Douglas fir stringer was $45 \mathrm{~mm}$ wide and $250 \mathrm{~mm}$ deep. Each flight of stairs was given two coats of polyurethane to seal the timber. The steel stairs consisted of the same riser and tread profile as well as the same stringer depth however the thickness of the stringer was reduced to approximately $6 \mathrm{~mm}$, the thickness of the steel plate used. 


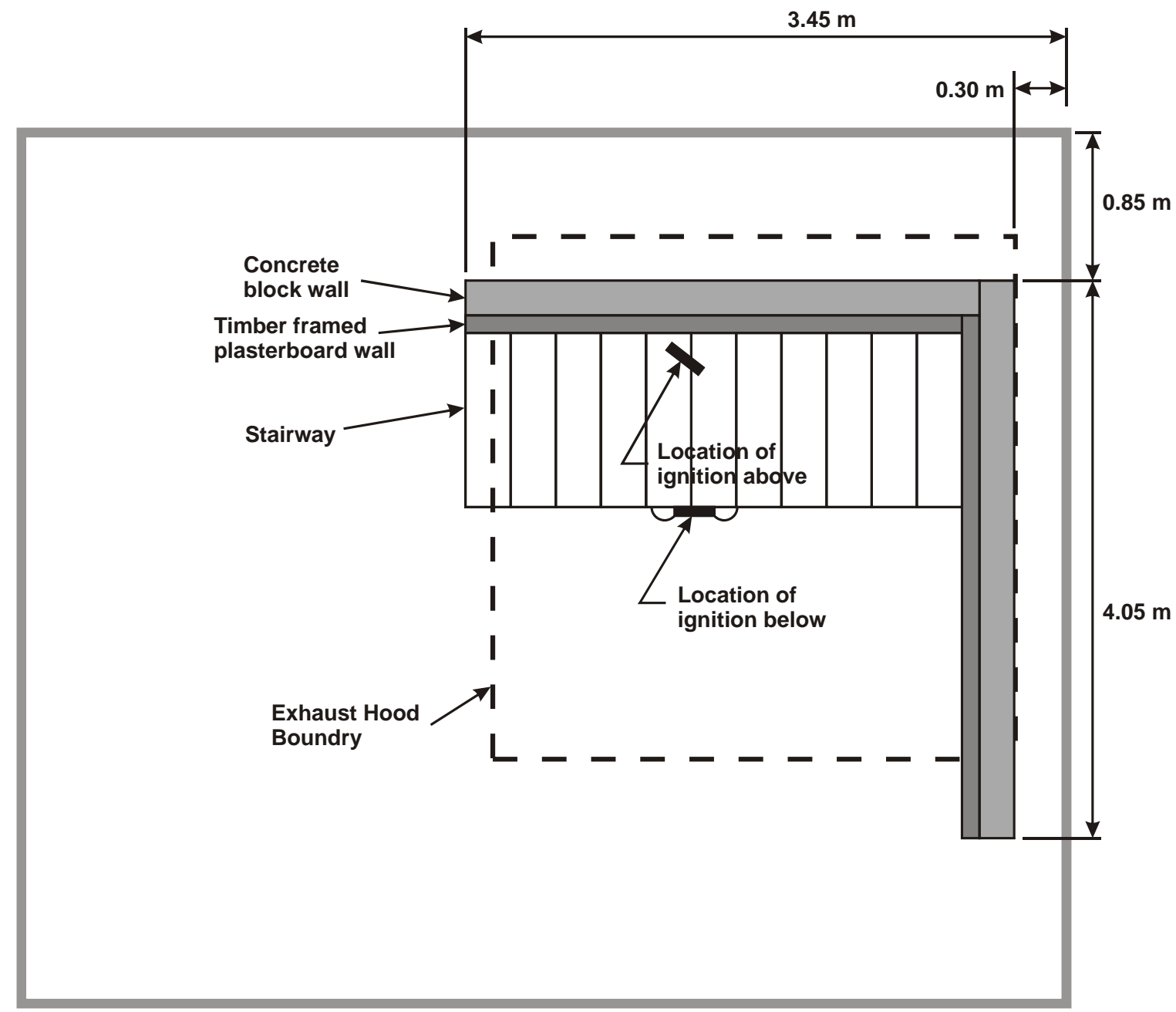

Fig. 1. Schematic drawing of the laboratory showing hood location, stair/wall arrangement, and the ignition locations for flammable liquid bottle.

In the first set of experiments, the stairs were omitted and only the concrete floor and two block walls were present. The primary variable in this set of experiments was the size of the bottle of petrol. The petrol used in these experiments was the standard 91 octane (lowest octane level commonly available) with a density of $0.735 \mathrm{~kg} / \mathrm{litre}$. The volume of the bottle range included $350 \mathrm{ml}, 750 \mathrm{ml}$, and $1000 \mathrm{ml}$ based on the commonly available bottles. A minimum of two replicate experiments were conducted for the three common bottles. One additional experiment with a $1500 \mathrm{ml}$ "special promotional" bottle was also conducted. The large promotional bottle is not common and only one sample could be obtained. To safely and reproducibly simulate the throwing of the bottle, the filled bottle was suspended on a chain $2.7 \mathrm{~m}$ above the floor. At time zero the bottle was released and allowed to swing along an arc to the point of ignition. The point of ignition was a steel knife blade with two electric arcs thus insuring the swinging bottle broke and the fuel spill immediately ignited. Fig. 2 is a photograph showing the fireball which erupts when the $1000 \mathrm{ml}$ glass bottle strikes the electrified knife blade. The two concrete walls are also visible in the photograph. 


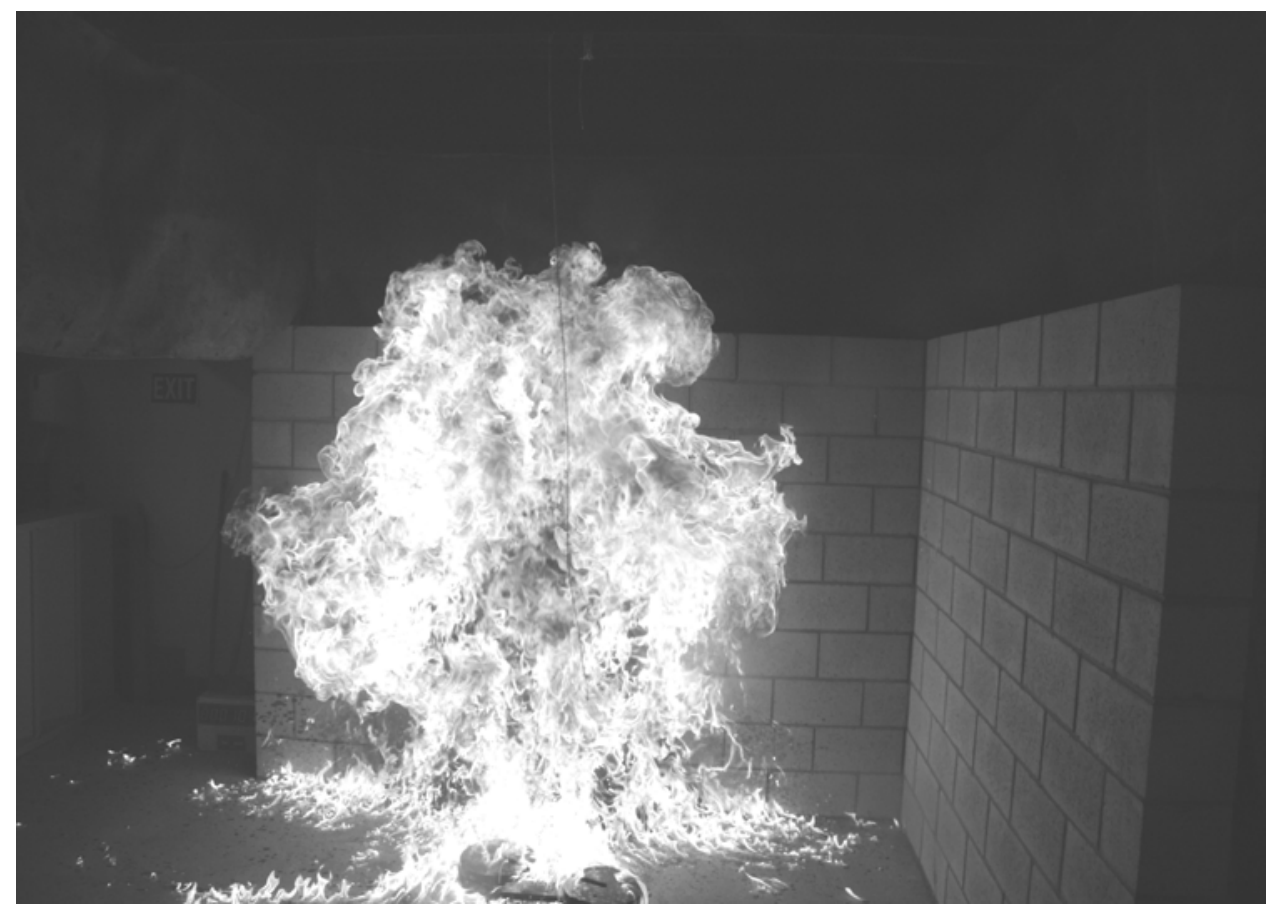

Fig. 2. Photograph showing the fireball immediately after the $1000 \mathrm{ml}$ glass bottle full of common petrol strikes the electric knife blade igniter.

The second set of experiments incorporated both wooden and metal stairs. In order to reduce the overall number of experiments, only $1000 \mathrm{ml}$ bottles were used. For most of the experiments the concrete walls were used, however, in eight of the experiments the walls were covered with gypsum wallboard which is also a common wall lining material in stairwells. The location of the ignition was also considered important, so the point of ignition was placed both above and below the stairs. To eliminate the affects of previous experiments each set of wooden stairs was only used twice, one experiment was completed with the ignition location on top of the steps and the second was under the steps. To ensure that this practice did not impact on subsequent experiments, the order of the experiments were varied with the first test on one flight of stairs being the on top and the first experiment of the repeat series being below the stairs.

\section{EXPERIMENTAL RESULTS}

The first set of experiments was conducted with only the two concrete block walls and floor in place and the volume of the fuel bottle was varied. A minimum of two replicates were conducted for each bottle except for the $1500 \mathrm{ml}$ case. The heat release rate history for each bottle volume is shown in Fig. 3 . The results show how rapidly the fire develops with the fire reaching its peak heat release rate within $10 \mathrm{~s}$ of ignition. The fire then burns at the peak heat release for 5-10 s. Within 15-20 s, the heat release rate begins to decay and the fire has nearly self extinguished within $60 \mathrm{~s}$. By $60 \mathrm{~s}$ the fire is only a few isolated small pools of fuel remaining in the uneven floor surface.

The times on the heat release rate curve should be interpreted with some caution due to the extremely short time frame for these experiments. Although the results have been time shifted to account for the transport and instrument lags the fires are so fast that temporal accuracy is somewhat suspect. The oxygen depletion technique is expected to give reasonable estimates of the heat release rate but is not expected to respond fast enough to completely capture the details of the early growth of the fire. As a verification that the results were within the expected range, the total heat release rate was estimated by integrating the area under the heat release rate curve. The total heat release rate was found to be within $10 \%$ of the expected value calculated by multiplying the total mass of fuel by the effective heat of combustion for the petrol. The effective heat of combustion was measured in the cone calorimeter with the same petrol used in the bottle experiments. 




Fig. 3. Heat release rate history for the four different bottle volumes $(350 \mathrm{ml}, 750 \mathrm{ml}, 1000 \mathrm{ml}$, and $1500 \mathrm{ml})$.

In the second set of experiments a flight of stairs was included in the setup. A $1000 \mathrm{ml}$ bottle was chosen for this series since it was the largest commonly available size. The bottle was broken and ignited either above or below the stairs. In either case, the stairs failed to reach sustained ignition and the fire self extinguished after all of the petrol was consumed. Fig. 4 shows exemplary heat release rate history results for the $1000 \mathrm{ml}$ petrol bottle ignited both above and below the timber stairs. It can be seen that there is little difference between the above and below ignitions. The results for the $1000 \mathrm{ml}$ no stair result is also included for comparison as the base case. Clearly the results indicate that the no stair case presents a more severe fire. In this paper the fire severity is defined as the magnitude of the peak heat release rate and the time to reach the peak. In Fig. 4 the no stair result is the most severe fire because the fire reaches a higher peak heat release rate and reaches the peak value sooner then timber stairs with above or below ignition.

Fig. 5 shows exemplary the heat release rate history results for the $1000 \mathrm{ml}$ petrol bottle ignited both above and below the metal stairs. Again the results for the $1000 \mathrm{ml}$ no stair result is included for comparison. Comparing the results in Fig. 5 with Fig. 4, the metal stairs result is slightly slower growing fire than either the timber stairs or no stair results. Fig. 6 shows exemplary the heat release rate history results for the 1000 $\mathrm{ml}$ petrol bottle ignited both above and below the timber stairs and gypsum wallboard walls. Comparing the results in Fig. 6 with Fig. 4, the gypsum wallboard represents a slightly slower growing fire than concrete block walls. Fig. 7 shows exemplary the heat release rate history results for the $1000 \mathrm{ml}$ petrol bottle ignited both above and below the timber stairs and gypsum wallboard walls. Comparing the results in Fig. 7 with Fig. 5, the gypsum wallboard represents a slightly slower growing fire than concrete block walls. 


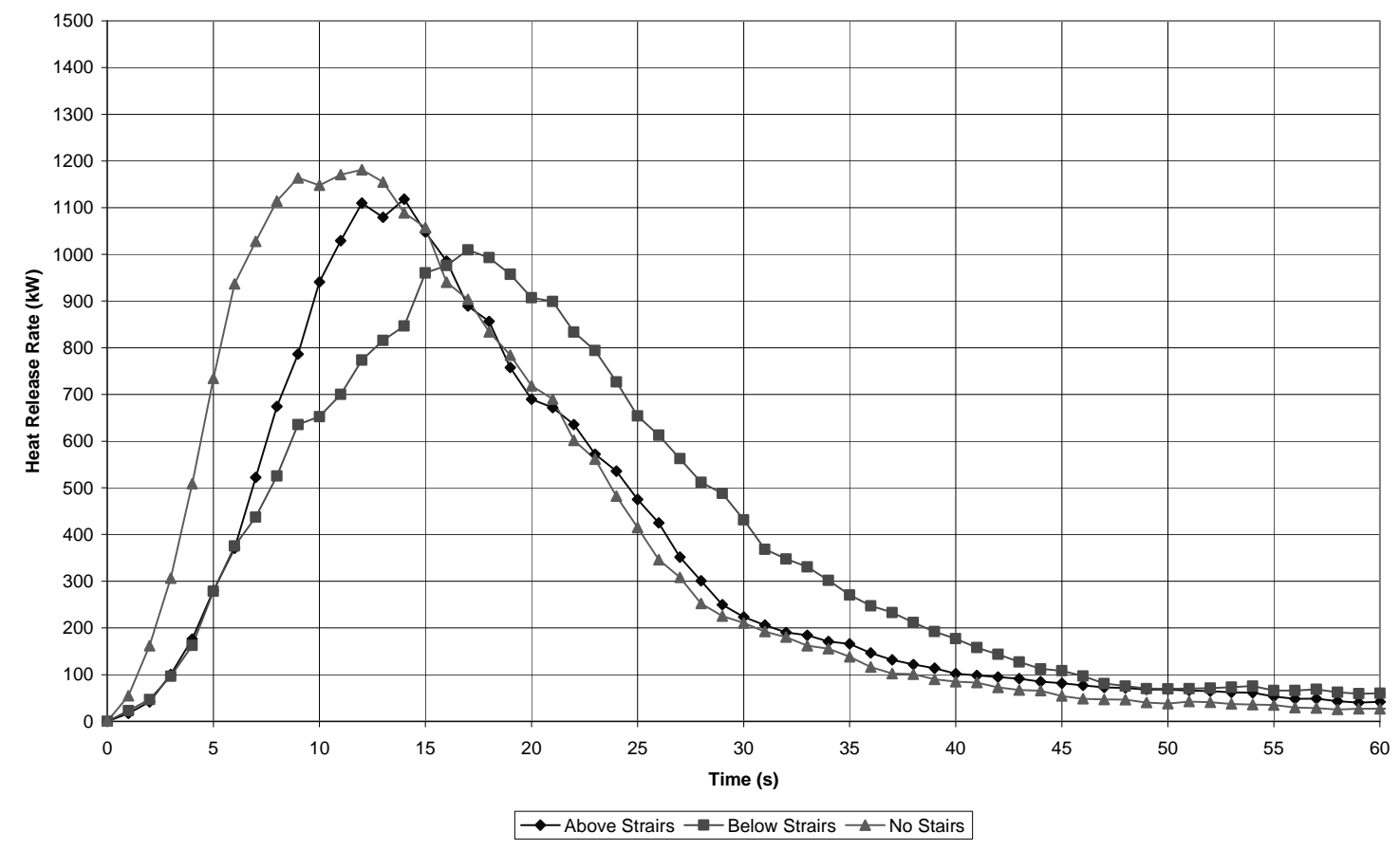

Fig. 4. Heat release rate history for the $1000 \mathrm{ml}$ bottle petrol fire ignited both above and below the timber stairs with concrete walls, the $1000 \mathrm{ml}$ bottle without stairs has been included for comparative purposes.

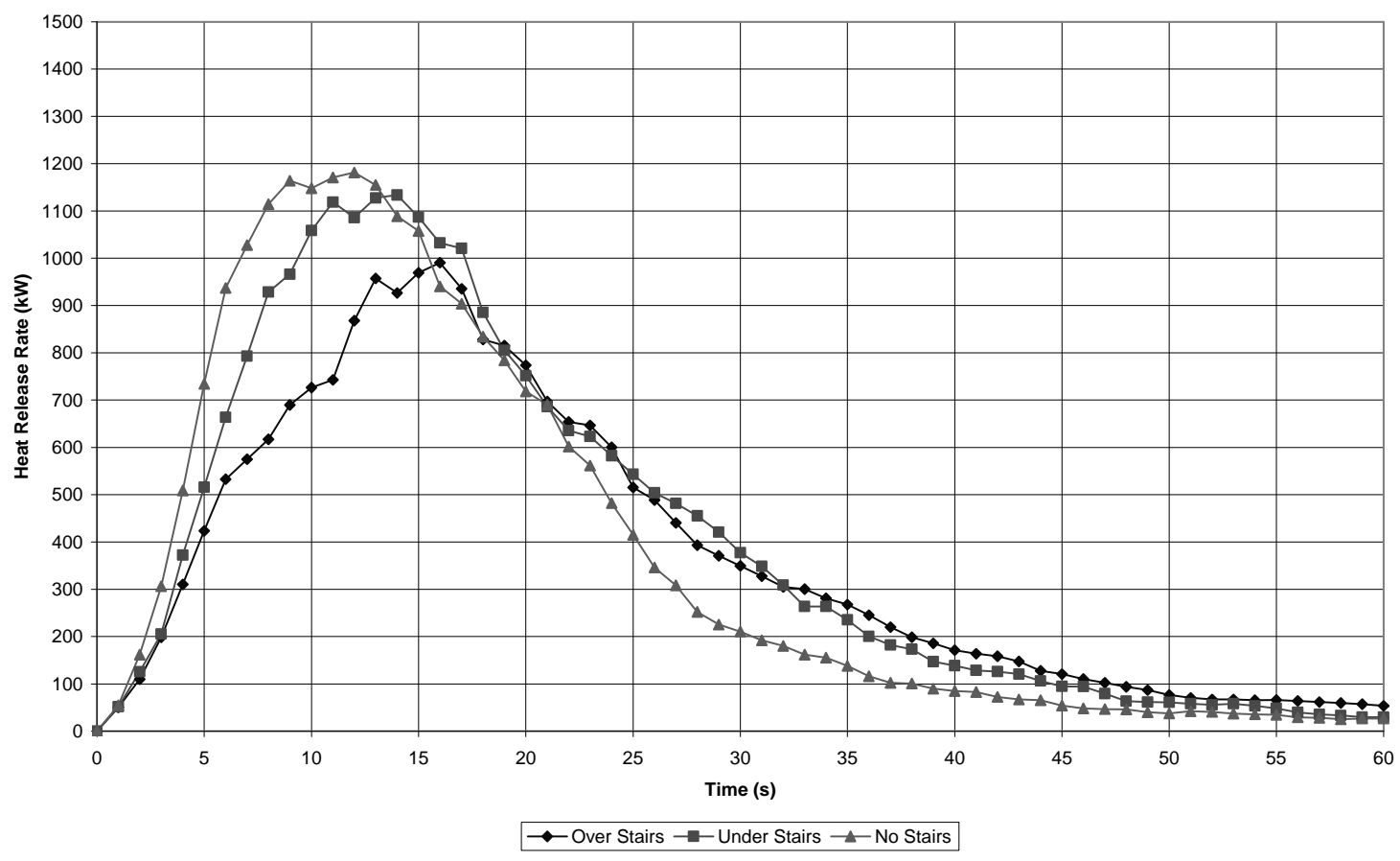

Fig. 5. Heat release rate history for the $1000 \mathrm{ml}$ bottle petrol fire ignited both above and below the metal stairs with concrete walls, the $1000 \mathrm{ml}$ bottle without stairs has been included for comparative purposes. 




Fig. 6. Heat release rate history for the $1000 \mathrm{ml}$ bottle petrol fire for the for the timber stairs with gypsum wallboard walls, the $1000 \mathrm{ml}$ bottle without stairs has been included for comparative purposes.

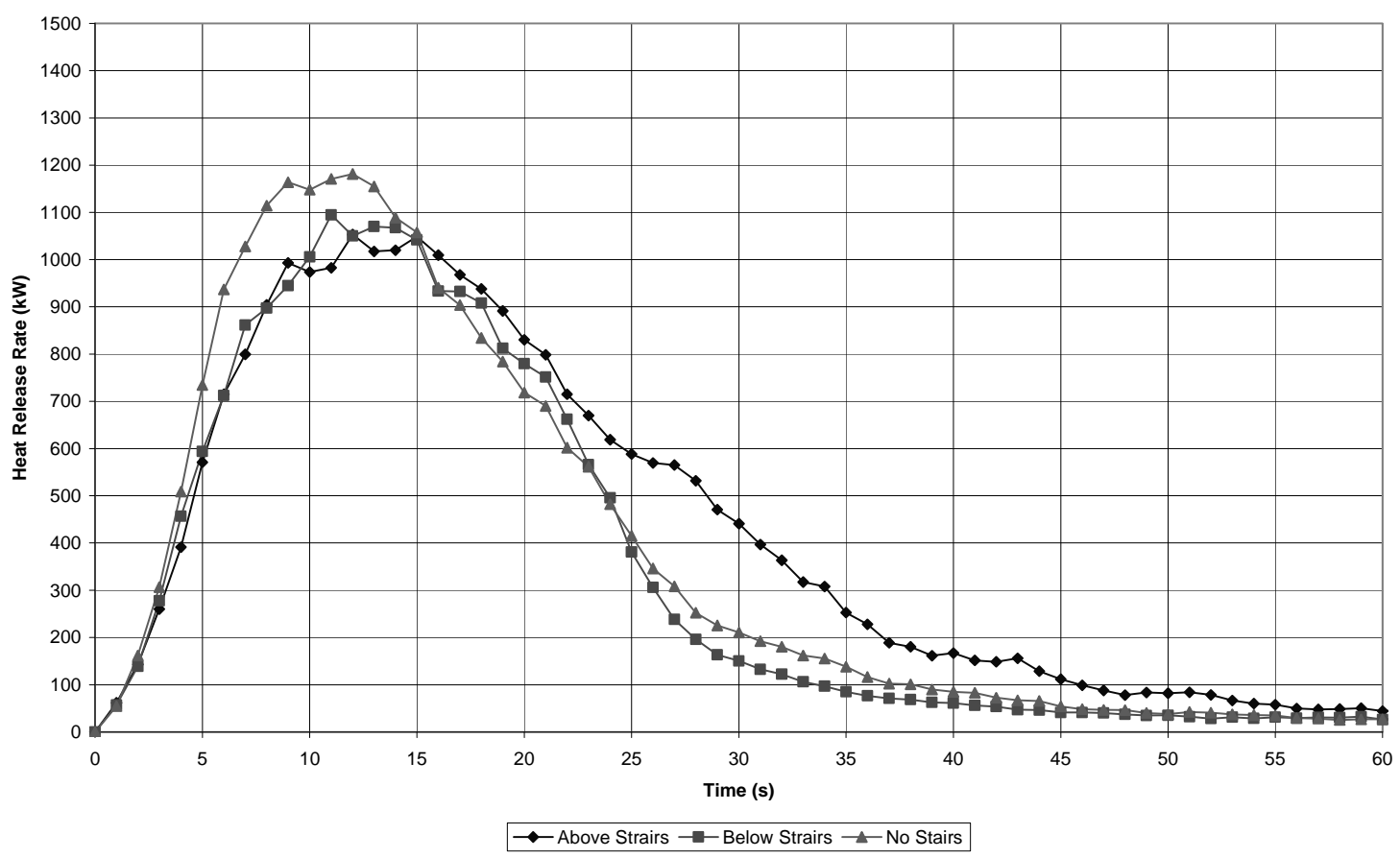

Fig. 7. Heat release rate history for the $1000 \mathrm{ml}$ bottle petrol fire for the for the metal stairs with gypsum wallboard walls, the $1000 \mathrm{ml}$ bottle without stairs has been included for comparative purposes. 
Table 2 gives a summary of all of the experiments reported here. Column 1 is the run \#, column 2 gives the material the stairs were constructed from either timber, steel, or not included, column 3 gives the location of the ignition source where if no stair was present then the ignition source was just above floor level or if the stairs are present than either above or below the stairs, column 4 gives the volume of the bottle which equates to the petrol volume. The results presented in columns 5 through 7 are considered a gross measure of the fire severity giving the peak heat release rate, time to peak heat release rate and the time to reach $50 \mathrm{~kW}$ after the peak heat release rate, respectively. The time to reach $50 \mathrm{~kW}$ after the peak heat release rate gives a crude indication how long the fire is a threat to an occupant entering the stairwell. Because the fire would often flicker in small pools for a relatively long times, the $50 \mathrm{~kW}$ value is a better indication of when the fire is no longer a hazard compared to using the time when no more flaming is present. The results in Table 2 show that in most runs the no stair fires were the most severe.

Table 2. Summary results form all 24 petrol bottle experiments.

\begin{tabular}{|c|c|c|c|c|c|c|c|}
\hline Run \# & $\begin{array}{c}\text { Stair } \\
\text { material }\end{array}$ & $\begin{array}{c}\text { Wall } \\
\text { material }\end{array}$ & $\begin{array}{c}\text { Ignition } \\
\text { Location }\end{array}$ & $\begin{array}{c}\text { Bottle } \\
\text { Volume } \\
(\mathrm{ml})\end{array}$ & $\begin{array}{c}\text { Peak Heat } \\
\text { release } \\
\text { rate }(\mathrm{kW})\end{array}$ & $\begin{array}{c}\text { Time to } \\
\text { peak heat } \\
\text { release } \\
\text { rate (s) }\end{array}$ & $\begin{array}{c}\text { Time to 50 } \\
\mathrm{kW}(\mathrm{s})\end{array}$ \\
\hline $1-1$ & None & Concrete & Floor & 350 & 440 & 11 & 30 \\
\hline $1-2$ & None & Concrete & Floor & 350 & 390 & 9 & 32 \\
\hline $1-3$ & None & Concrete & Floor & 750 & 1010 & 11 & 49 \\
\hline $1-4$ & None & Concrete & Floor & 750 & 880 & 11 & 51 \\
\hline $1-5$ & None & Concrete & Floor & 1000 & 1310 & 11 & 56 \\
\hline $1-6$ & None & Concrete & Floor & 1000 & 1350 & 14 & 46 \\
\hline $1-7$ & None & Concrete & Floor & 1000 & 1200 & 9 & 54 \\
\hline $1-8$ & None & Concrete & Floor & 1500 & 1690 & 12 & 63 \\
\hline $2-1$ & Timber & Concrete & Above & 1000 & 1300 & 12 & 56 \\
\hline $2-2$ & Timber & Concrete & Above & 1000 & 1000 & 17 & 54 \\
\hline $2-3$ & Timber & Concrete & Below & 1000 & 1260 & 17 & 61 \\
\hline $2-4$ & Timber & Concrete & Below & 1000 & 1100 & 24 & 62 \\
\hline $2-5$ & Timber & Gypsum & Above & 1000 & 1200 & 17 & 69 \\
\hline $2-6$ & Timber & Gypsum & Above & 1000 & 1020 & 20 & 75 \\
\hline $2-7$ & Timber & Gypsum & Below & 1000 & 1030 & 23 & 66 \\
\hline $2-8$ & Timber & Gypsum & Below & 1000 & 1230 & 18 & 66 \\
\hline $3-1$ & Steel & Concrete & Above & 1000 & 1130 & 14 & 62 \\
\hline $3-2$ & Steel & Concrete & Above & 1000 & 1030 & 12 & 60 \\
\hline $3-3$ & Steel & Concrete & Below & 1000 & 1340 & 12 & 55 \\
\hline $3-4$ & Steel & Concrete & Below & 1000 & 1170 & 15 & 55 \\
\hline $3-5$ & Steel & Gypsum & Above & 1000 & 1170 & 14 & 56 \\
\hline $3-6$ & Steel & Gypsum & Above & 1000 & 1600 & 10 & 51 \\
\hline $3-7$ & Steel & Gypsum & Below & 1000 & 1260 & 13 & 43 \\
\hline $3-8$ & Steel & Gypsum & Below & 1000 & 1170 & 10 & 47 \\
\hline
\end{tabular}

Because these experiments were so transient and the mass loss was not measured for practical reasons, the species production rates and effective heat of combustion were obtained from cone calorimeter results. Three replicate tests were conducted in the cone burning a pan of the identical petrol used in the bottle experiments. The petrol was ignited with an electrical arc from the igniter and burned with zero external heat flux. Measurements were made throughout the test with the values reported here were during the quasi steady burning. The effective heat of combustion was calculated by dividing the heat release rate by the mass loss rate. Carbon dioxide and carbon monoxide were measured using non-dispersive infrared analysers and the smoke production was taken from an optical laser technique. The averages of the three replicate tests are summarised below: 
Effective heat of combustion

Carbon dioxide yield

Carbon monoxide yield

Soot yield
$40 \mathrm{MJ} / \mathrm{kg}$

$3 \mathrm{~g} / \mathrm{g}$ fuel

$0.04 \mathrm{~g} / \mathrm{g}$ fuel

$0.04 \mathrm{~g} / \mathrm{g}$ fuel

It should be noted that these fires were conducted in an open calorimeter with ample makeup air for combustion of the fuel. This geometry is expected to give the largest heat release rate and most complete combustion of the fuel. In the case of a closed compartment the heat release rate would be expected to be lower with less complete combustion of the fuel and higher species production.

\section{CONCLUSIONS}

Deliberately lit fires can and do occur in all occupancy classifications. Based on a review of the New Zealand Fire Service Incident Reporting system data, for most occupancy types, the deliberately lit fire is generally expected to be accounted for by the typical design fire scenarios. However, the statistical analysis does indicate that for certain occupancies deliberately lit fires represent disproportionate number of fire incidents. The occupancies include:

- $\quad$ Prisons

- Psychiatric institutions

- Schools

- $\quad$ Crowd activities

- $\quad$ Attached accommodation

For these occupancies the deliberately lit fire scenario should be explicitly considered within the Fire Engineering Brief.

In certain cases, such as single means of escape multistory buildings, a fire in the exitway should be considered in the Fire Engineering Brief. In such a building the stairwell is the most vulnerable part of the exitway. Typically the stairwell is noncombustible and therefore the only fuel available is the introduced fuel such as accelerants. The results presented in this paper show that a one litre bottle of petrol broken in a noncombustible enclosure will result in a fire with a peak heat release rate of $1200 \mathrm{~kW}$ and will reach that peak in approximately $10 \mathrm{~s}$. The fire will remain at the peak level for another $10 \mathrm{~s}$ before entering into a decay phase lasting an additional $40 \mathrm{~s}$.

In most countries storage under the stairway is not permitted, however, it is not difficult to find a stairway where the occupants have placed combustible material under the stairs. For this reason, future research should include light combustible material under the stair to simulate storage. Although the potential items stored under the stairs are numerous, some reasonable estimate to bound the problem is possible. Clearly the installation of a sprinkler under the stairs at the ground floor would be prudent engineering. Although a sprinkler may not activate in time to have an effect on the initial flammable liquid fire, it would be expected to have its normal efficacy where additional combustible materials are present.

\section{ACKNOWLEDGEMENT}

The authors would like to acknowledge the New Zealand Fire Service Commission for their continued financial support of the University of Canterbury Fire Engineering program. Further we would like to thank Grant Dunlop and Bob Wilsea-Smith for their assistance with the experiments. 


\section{REFERENCES}

[1] Stone, F.H., “Bombs and Buildings”, Fire Engineering, 157, 2004, pp. 160-168.

[2] Department of Building and Housing, Compliance Document for the New Zealand Building Code Clauses C1, C2, C3, C4 Fire Safety, October 2005.

[3] Fleischmann, C. M. and Caldwell, C. A., "Relative Risk Assessment for Single Means of Escape High Rise Apartment Buildings In New Zealand”, Symposium on Highrise Fire Safety, University of Cantaberia, Santander, Spain, 2006.

[4] Department of Building and Housing, Determination 2005-109 Single means of escape from a high-rise apartment building, July 2005.

[5] Department of Building and Housing, Determination 2005-134 Single means of escape from a high-rise apartment building at 2-30 Beach Road, Auckland City, September 2005.

[6] Department of Building and Housing, Determination 2005-168 Single means of escape from a high-rise apartment building at 7 Scotia Place, Auckland City, December 2005.

[7] Department of Building and Housing, Determination 2006-52 Single means of escape from a high-rise apartment building at 18 Turner Street and 17-19 Waverly Street, Auckland City, June 2006.

[8] Putorti, A. D., "Flammable and Combustible Liquid Spill/Burn Patterns", National Institute of Justice, National Institute of Justice, NIJ Report 604-00, March 2001.

[9] Richards, P. L. E., “Characterizing a Design Fire for a Deliberately Lit Fire Scenario”, Masters Thesis, University of Canterbury, 2008.

[10] Woodward, D.C., “Firesetting American Style”, Fire Prevention, Issue 258, April 1993, pp 17-20.

[11] DeHaan , J. D., “Kirk’s Fire Investigation”, $5^{\text {th }}$ ed., Prentice Hall, New Jersey, 2002.

[12] Enright, P. A., "Heat Release Rate and the Combustion Behaviour of Upholstered Furniture", PhD Thesis, University of Canterbury, 1999.

[13] Compliance Document for the New Zealand Building Code, Clauses D1 - Access Routes, Dept of Building and Housing, 2006. 